\title{
A PERCEPÇÃO DE COMPRADORES SOBRE A QUALIDADE DA CARNE SUÍNA IN NATURA NO MERCADO VAREJISTA DE CAMPO GRANDE (MS)
}

\author{
Celso Correia de Souza ${ }^{1}$ \\ Rafael Gabriel ${ }^{2}$ \\ José Francisco dos Reis Neto ${ }^{3}$ \\ Daniel Massen Frainer ${ }^{4}$
}

\section{RESUMO}

Este estudo teve como objetivo avaliar a percepção de compradores sobre a qualidade da carne suína in natura no mercado varejista de Campo Grande (MS). Uma amostra aleatória de 400 indivíduos da cidade foi investigada, em lugares perto de pontos de venda de carne suína fresca. Foram realizadas estatísticas univariadas, bivariadas e multivariadas concluindo que $76,75 \%$ da população consumiam carne suína fresca. Destes, $49 \%$ consumiram pelo menos uma vez por semana. O preço não influenciava a frequência de consumo de carne suína, mas a facilidade de preparação, principalmente, em relação às mulheres que têm pouco tempo para fazer as refeições em casa. Além disso, oferecendo uma maior variedade de cortes poderia trazer um aumento na frequência de consumo desta carne. Verificou-se que ainda existem fatores que inibem o consumo de carne suína. No entanto continua a ser a percepção de que a carne tem uma quantidade elevada de colesterol e de gordura, problemas de higiene com risco para a saúde que tem limitado a uma maior procura. O uso do marketing pode melhorar a imagem da carne suína para o consumidor, a fim de eliminar preconceitos sobre este produto e mostrar seus pontos fortes como o sabor e maciez.

Palavras-chave: carne gorda, comportamento do consumidor, risco à saúde, saúde animal.

\footnotetext{
${ }^{1}$ Graduado em matemática. Mestre em Matemática. Doutor em Engenharia Elétrica. Professor do Programa de Mestrado em Produção e Gestão Agroindustrial da Universidade Anhanguera-Uniderp. E-mail: csouza939@gmail.com

${ }^{2}$ Graduado em Administração. Mestre em Produção e Gestão Agroindustrial da Universidade AnhangueraUniderp. E-mail: rafael.gabriel@ifms.edu.br

${ }^{3}$ Graduado em Engenharia Elétrica. Mestre em Administração. Professor da Universidade AnhangueraUniderp. E-mail: jfreisneto@terra.com.br.

${ }^{4}$ Graduado em Ciências Econômicas. Mestre em Engenharia de Produção. Doutor em Economia. Professor da Universidade Estadual de Mato Grosso do Sul. E-mail: danielfrainer@gmail.com.
} 


\title{
PERCEPTION OF BUYERS ON THE QUALITY OF PORK MEAT MARKETING RETAILER OF CAMPO GRANDE (MS)
}

\begin{abstract}
This study aimed to evaluate the perception of buyers on the quality of pork meat in the retail market of Campo Grande (MS). A random sample of 400 individuals of the city was investigated in places close to points of sale of pork meat. Were performed univariate statistics, bivariate and multivariate concluded that $76.75 \%$ of the population consumed pork meat. Of these, $49 \%$ had consumed at least once a week. The price did not influence the frequency of consumption of pork meat, but the ease of preparation, particularly in relation to women who have little time to make meals at home. Also, providing a wider range of cuts could bring an increase in the frequency of consumption of meat. It was found that there are factors which inhibit the consumption of pork meat, however, remains the perception that the meat has a high amount of cholesterol and fat, however, remains the perception that the meat has a high amount of cholesterol and fat, you have problems with hygiene risk to health which has limited higher demand. The use of marketing can improve the image of pork meat to consumers in order to eliminate prejudices about this product and show its strengths as the flavor and tenderness.
\end{abstract}

Keywords: Animal health, consumer behavior, fat meat, health risk.

\section{INTRODUÇÃO}

A carne suína é consumida em todo mundo, possuindo grande importância econômica em diversos países. A cadeia produtiva da carne suína se tornou altamente competitiva no Brasil, com significativas melhorias tanto na produção quanto na industrialização e comercialização.

A produção brasileira de carne suína aumentou 4,9\% em 2015 ante 2014, atingindo 3,86 milhões de toneladas. O consumo per capita do produto também cresceu, chegando a 15,1 quilos por habitante/ano, crescimento de $2,5 \%$. O país foi o quarto maior produtor mundial de carne suína em 2015, ficando atrás da China que produziu 62,89 milhões de toneladas, a União Europeia com 22,45 milhões de toneladas e os Estados Unidos com 9,81 milhões de toneladas (ROPPA, 2016).

Além dos fatores de mercado, também influenciou esta elevação de produção e consumo as iniciativas promovidas em todo o país de conscientização da população sobre os valores nutricionais e a qualidade da carne suína. Como exemplo, basta observar que os consumidores europeus e asiáticos têm uma preferência em consumir mais a carne suína em relação aos outros tipos de carnes, como a bovina e aves.

Há algumas décadas a carne suína era percebida como uma carne "gorda" e "prejudicial à saúde", mas em decorrência do aprimoramento e seleção no sistema de produção, que sofreu profundas transformações com o início da criação de suínos de baixa quantidade de gordura.

Para que as empresas que atuam na cadeia produtiva da carne suína possam criar vantagens competitivas sustentáveis por meio da implementação de estratégias mercadológicas eficazes, é imprescindível compreender as mudanças nas necessidades e desejos dos consumidores. Desse modo, entender quais os atributos da carne suína são mais (ou menos) valorizados pelos consumidores e que 
atende, ou não, às suas demandas, é uma condição fundamental para que essas empresas se tornem competitivas e sustentáveis.

O entendimento das variáveis que influenciam o comportamento do consumidor permite justificar as razões das escolhas dos produtos. Essas influências podem ser de ordem interna ou externa. As influencias de ordem interna são fatores psicológicos, como motivação, preconceito, atitudes e personalidade, enquanto, as externas são família, grupos e cultura.

Das variáveis elencadas acima, a que mais afeta o comportamento do consumidor é a cultura, pois, certo produto pode ser valorizado numa cultura e não ter valor algum em outra cultura. O que pode ser uma questão cultural é o fato da carne suína ser a terceira carne na preferência do brasileiro, sendo o seu consumo per capta de $15,1 \mathrm{~kg} / \mathrm{ano}$, enquanto o da carne de frango e o de carne bovina é de 26 e 40,0 kg/ano per capta, respectivamente.

A carne suína é hoje a fonte de proteína animal mais consumida no mundo, tendo ultrapassado a preferência dos consumidores pela carne bovina, principalmente, na Europa e países asiáticos. Há algumas décadas a carne suína era percebida como uma carne "gorda" e "forte", que fazia mal e era prejudicial à saúde, mas hoje, com as constantes transformações que vem passando o seu sistema de produção iniciou-se a criação de suínos com baixos níveis de gordura (ABIPECS, 2012).

Pesquisa realizada com consumidores gregos verificou que esses estão satisfeitos com a carne suína nos atributos sabor, maciez e suculência, existindo também um segmento, de mais idade, que prefere carne suína magra, devido a preocupação com a saúde. Por outro lado, o alto preço do produto nos países europeus é um inibidor de um maior consumo da a carne suína tanto in natura quanto processada (PAPANAGIOTOU et al., 2013; RESANO et al., 2011).

A questão ambiental ligada aos dejetos suínos também é uma outra preocupação dessa atividade agropecuária brasileira, que a partir da década de 1970 começou a se desenvolver de forma significativa. Segundo Mera et al. (2011), a questão ambiental vem se tornando assunto importante no atendimento à demanda interna e mundial.

Já, uma outra pesquisa sobre a carne suína com consumidores de quatro países europeus França, Dinamarca, Suécia e Reino Unido, mostrou que os mesmos estão preocupados com a forma do sistema produtivo dessa carne, ou seja, segurança alimentar, bem-estar animal e da poluição ambiental. Verificou-se também, que ao colocar etiquetas em cortes da carne suína com informações sobre a origem dessa carne (local de criação), percebeu-se uma preferência pela carne suína proviniente do seu próprio país, pagando até $5 \%$ a mais em detrimento da cane suína importada (DRANSFIELD et al., 2005).

É fato que a propaganda tem muita influência sobre o consumidor na sua decisão de comprar determinado produto, pois, um estudo realizado em 2008 na Coreia do Sul indicou que uma imagem negativa (publicidade negativa) em relação à segurança da carne bovina dos Estados Unidos da América fez diminuir o consumo dessa carne pelos consumidores coreanos e, aumentar o consumo de carne suína (YOUN et al., 2012). No Brasil existem preconceitos sobre a carne suína in natura e derivados, de que apresentam altos riscos à saúde devido à alta quantidade de colesterol e gordura, bem como, sua relação com a transmissão de doenças. A falta de informações sobre a carne suína pode estar prejudicando um aumento do seu consumo (FARIA et al., 2006).

Sobre a questão do teor de gordura e colesterol que eram as preocupações de $38,4 \%$ dos consumidores de Belo Horizonte (MG), e que inibia o consumo de carne suína, se caracteriza como um desconhecimento das qualidades dessa carne, 
pois alguns dos seus cortes têm o mesmo teor de gordura e colesterol, ou até menos, quando comparados a alguns cortes de carne bovina ou de frango. No entanto, o sabor é o principal motivo para o consumo de carne suína in natura por esses consumidores, sendo que $7 \%$ consumiam diariamente; $28,4 \%$ uma vez por semana; $26,2 \%$ de duas a três vezes por semana; $11,2 \%$ quinzenalmente; $26,2 \%$ mensalmente e 1\% não responderam (FARIA et al., 2006).

Segundo Saab (2005) e Schlindwein e Kassouf (2006), o sabor é, certamente, o atributo que traz mais satisfação em relação ao consumo da carne suína no Brasil, sendo que o seu consumo só não é maior devido a pouca variedade de cortes, questões de disponibilização do produto nos pontos de venda e devido à questão cultural, entre outros. Desse modo, os limitantes para uma maior demanda da carne suína são os seguintes: a falta de cortes específicos de baixo de valor agregado para a população de baixa renda e os mitos e lendas de que a carne suína afeta negativamente a saúde.

Também, em pesquisa com consumidores da cidade de Campinas, SP, verificou que os atributos gordura, colesterol, calorias e segurança (confiabilidade) influenciam na intenção de consumir carne suína (FONSECA; SALAY, 2008). Para um melhor entendimento sobre o consumo de carne suína, especificamente, em Campo Grande (MS), a análise de alguns tópicos sobre o comportamento do consumidor em relação aos alimentos se faz necessário.

O comportamento do consumo de alimentos ocorre pela interação de três fatores: alimentos, consumidor e contexto de consumo. Estão relacionadas ao alimento as influências do cheiro, sabor, gosto, nutrientes e embalagem. Ao consumidor estão associadas às variáveis: hábitos, cultura, personalidade, humor e psicologia. Alguns atributos como as condições em que a carne suína foi produzida não são percebidos pelos consumidores. Por isso, garantir o respeito e a responsabilidade do alimento será um grande desafio dos empresários e produtores, padronizando processos visando criar uma percepção de confiança para o consumidor (ALCÂNTARA et al., 2008; ELAINE, 2008).

Segundo Spers (2011) o consumidor percebe alguns atributos relacionados aos alimentos e os classificam em qualidades extrínsecas (percebido facilmente pelo consumidor pelas características do ambiente externo, como: selo de qualidade, marca, aparência e outros) e intrínsecas (qualidade do produto, segurança alimentar, nutrição e outros). Para a tomada de decisão de compra, os aspectos que antes eram avaliados apenas pelos quesitos preço, conveniência e aparência, agora são avaliados pelas qualidades extrínsecas e intrínsecas.

Para Vitti et al. (2011) a avaliação dos valores perceptivos do consumidor torna-se importante para a efetiva realização de uma transação econômica. Ao fornecedor de carne suína cabe avaliar o que está sendo apresentado como produto, sua imagem e divulgação. A carne suína é de grande importância para a alimentação humana, contribuindo com diversas vitaminas e sais essenciais para um bom funcionamento do organismo, auxiliando na prevenção de várias doenças (COELHO, 2007).

Sob o aspecto da qualidade, o consumidor avalia sobre as dimensões primárias, por exemplo, aquelas propostas por Garvin (1992): qualidade percebida (vantagem comparativa com outros produtos semelhantes ou substitutos), conformidade (características iniciais prometidas), confiabilidade (experiência do consumidor e a sua comprovação ao prometido na dimensão conformidade), estética (cheiro, sabor, aparência), durabilidade (vida útil do produto) e atendimento (rapidez e facilidade para a aquisição do produto). As dimensões da qualidade percebida, conformidade, confiabilidade e estética podem estar ligadas à percepção do consumidor de carne suína in natura ao sistema de criação do animal, à 
manipulação da carne nos frigoríficos e supermercados, à conservação e aspectos visuais.

De acordo com Ventura (2010), observam-se mudanças significativas no perfil do consumidor. Novos mercados estão em crescimento e outros devem ser resgatados. A crescente busca pela melhoria da qualidade de vida pode ser percebida pelo aumento do consumo de serviços e produtos saudáveis, entre eles, os mais evidentes são os produtos do segmento de alimentação. Apesar dos estudos relacionados à percepção dos consumidores em relação a diversos produtos serem bastante difundidos no Brasil, o seu histórico de pesquisas de campo em relação à percepção dos consumidores ainda é recente e incipiente no país, principalmente, em relação à carne suína. Assim, esta pesquisa se justifica pela sua atualidade e, em parte, por sua originalidade em relação à região pesquisada, a cidade de Campo Grande, Mato Grosso do Sul.

Nesse sentido, este estudo teve como objetivo analisar o perfil do consumidor de carne suína em Campo Grande (MS). Especificamente: a) caracterizar o perfil demográfico do consumidor de carne suína, levando em consideração questões como idade, sexo e grau de escolaridade e b) agrupar os consumidores em segmentos considerando as características demográficas e suas percepções a respeito da carne suína.

\section{MÉTODO}

A presente pesquisa, quanto à sua natureza, foi caracterizada como aplicada (pois visou gerar conhecimento prático), quanto ao seu tipo, foi caracterizada como exploratória (pois visou gerar mais conhecimento sobre o assunto) e descritiva (pois, na coleta e análise dos dados não houve interferência do pesquisador na manipulação de variáveis). Quanto ao seu procedimento, caracterizou-se como uma pesquisa de campo, tendo como objeto da pesquisa a população adulta de Campo Grande, distribuída nas sete regiões administrativas da cidade (grandes bairros).

A coleta de dados foi feita através de entrevistas com base num formulário semi-estruturado envolvendo aspectos demográficos, seguido de perguntas sobre hábito de consumo e não consumo de carne suína, percepção e exigência do consumidor em relação à carne suína, assim como, perguntas que buscavam mostrar quais fatores contribuíam para inibir o consumo da carne suína em relação às carnes de frango e bovina (KOTLER, 1998; LAS CASAS 2009; COBRA, 2009).

Nas entrevistas procurou-se observar a proporção entre os gêneros masculino e feminino que, de acordo com o IBGE (2010), na cidade de Campo Grande é de, aproximadamente, cinquenta e um por cento de mulheres e quarenta e nove por cento de homens.

Em algumas questões, para melhor compreensão da importância de cada atributo da carne suína, foi utilizada a escala de Likert, variando de 1 a 7 , sendo: $1=$ Discordo plenamente, 2 = Discordo, 3 = Discordo parcialmente, $4=$ Nem concordo e nem discordo, 5 = Concordo parcialmente, 6 = Concordo, $7=$ Concordo plenamente. Essa escala proporciona capturar variáveis qualitativas e transformá-las em quantitativas. Essa mesma escala também foi utilizada em algumas questões para verificar o grau de conhecimento dos consumidores sobre as vantagens $e$ desvantagens de se consumir carne suína.

Tendo como universo de pesquisa a população adulta da cidade de Campo Grande, com 612.337 indivíduos (IBGE, 2010), o tamanho mínimo da amostra foi de 384 indivíduos, em que foi utilizada nesse cálculo a metodologia de Fonseca e Martins (2006), considerando um nível de confiança de 95\%, proporção $p=0,50$, para se obter a maior amostra possível e, uma margem de erro amostral de $5 \%$. 
Foram realizadas 400 entrevistas. Com a intenção de buscar representatividade da população, as entrevistas foram distribuídas estrategicamente próximas a pontos de vendas de carne suína localizados nas sete regiões administrativas da cidade de Campo Grande: Centro, Segredo, Prosa, Bandeira, Anhanduizinho, Lagoa e Imbirussu.

As entrevistas foram realizadas no período de 05 a 31 de janeiro de 2013. As informações coletadas foram tabuladas e analisadas utilizando-se os softwares Sphinx e IBM-SPSS (SPHINX, 2016; IBM-SPSS, 2016). Foram realizadas análises univariadas, bivariadas e multivariadas. Nas análises univariadas foram observadas as frequências das variáveis para caracterizar o perfil do consumidor e não consumidor de carne suína. A análise bivariada tratou do cruzamento de informações visando à determinação do comportamento do consumidor e não consumidor de carne suína, com o cálculo do nível de associação entre os pares de variáveis, por meio do teste do Qui-quadrado, com o cálculo do parâmetro de significância p. Para p menor ou igual a 5\%, a associação das variáveis é significativa, caso contrário, a associação não é significativa.

Por último, de forma complementar, procedeu-se a uma análise multivariada dos dados utilizando o método de análise fatorial com a função principal de reduzir o número original de variáveis de alguns blocos de questões que possuem a mesma natureza, de sorte que os fatores independentes extraídos pudessem explicar, de forma simples e reduzida as variáveis originais agrupadas. O tamanho da amostra para a realização da análise fatorial obedeceu ao critério recomendado por Malhotra (2001) e Hair et al. (2009), de que cada variável possua, pelo menos, cinco observações.

Ainda, segundo Hair et al. (2009), a matriz de dados deve apresentar correlações suficientes para justificar a aplicação da análise fatorial. As etapas para o desenvolvimento da análise fatorial foram as seguintes: (a) cálculo da matriz de correlação de todas as variáveis; (b) determinação do número e extração dos fatores; (c) rotação dos fatores, transformando-os com a finalidade de facilitar a sua interpretação; (d) cálculo dos escores fatoriais, sendo que valores maiores de 0,6 indicam uma análise fatorial apropriada; (e) nomeação e interpretação de cada fator obtido.

\section{RESULTADOS E DISCUSSÃO}

Inicialmente, foi determinado o perfil do consumidor da cidade de Campo Grande e analisado os parâmetros sobre as propriedades da carne suína, dos pontos de vistas de consumidores e não consumidores, respectivamente. Posteriormente, foi analisado o comportamento do consumidor e não consumidor da carne suína relativos aos atributos dessa carne e, finalmente, foram realizados agrupamentos dos segmentos de consumidores e não consumidores, separadamente, considerando as características demográficas e suas percepções a respeito da carne suína.

Sobre o perfil do consumidor, que faz compras no mercado varejista de Campo Grande (MS), concluiu-se que os consumidores de Campo Grande eram $52,8 \%$ de mulheres e $47,2 \%$ de homens, valores próximos aos de (IBGE, 2010). Mais de $80 \%$ dos consumidores estavam na faixa etária dos 18 aos 49 anos e, em torno de $82,6 \%$ possuía renda entre $R \$ 500,00$ e $R \$ 3.000,00$. Um total de $28 \%$ dos consumidores tinha até ensino fundamental completo e $72 \%$ de ensino médio incompleto até ensino superior completo. Em torno de $73,6 \%$ das famílias eram compostas de 3 ou mais membros. 


\subsection{CONSUMIDOR DE CARNE SUÍNA IN NATURA EM CAMPO GRANDE}

Em relação ao consumo de carne suína na cidade de Campo Grande, observou-se que $76,8 \%$ da população consumia essa carne. Daqueles que consumiam, $43,7 \%$ consumiam de uma a duas vezes por semana, $13,6 \%$ consumiam mais de duas vezes por semana, 1,7\% uma vez por mês, 10,9\% a cada três meses, 9,6\% de uma a duas por ano e 20,5\% somente em ocasiões especiais (em algumas datas festivas). Na pesquisa de Faria et al. (2006), com consumidores de Belo Horizonte (MG), constatou-se que 7\% consumiam diariamente, $28,4 \%$ uma vez por semana; $26,2 \%$ de duas a três vezes por semana; $11,2 \%$ quinzenalmente, $26,2 \%$ mensalmente e $1 \%$ não responderam.

Aos consumidores de carne suína foram feitas quatorze perguntas sobre os atributos dessa carne que os motivavam a consumirem. As perguntas foram feitas em escala de Likert de 7 pontos, variando de $1=$ discordo plenamente até $7=$ concordo plenamente. Foram calculadas as médias aritméticas, os desvios padrão e os coeficientes de variação, para facilitar as análises e servirem como indicadores. As respostas estão na Tabela 1. 
Tabela 1 - Parâmetros (média aritmética, desvio padrão (DP) e coeficiente de variação $\mathrm{CV}$ ) sobre os atributos da carne suína, do ponto de vista dos consumidores dessa carne. Campo Grande, 2013.

\begin{tabular}{clccc}
\hline $\mathbf{N}$ & Atributo da carne suína (consumidor) & Média & DP & $\mathbf{C V}(\%)$ \\
\hline $\mathbf{1}$ & Carne suína é uma carne macia & 5,99 & 0,92 & 15,36 \\
$\mathbf{2}$ & Carne suína apresenta um bom sabor & 5,84 & 1,21 & 20,72 \\
$\mathbf{3}$ & A carne suína apresenta alta quantidade de gordura & 5,43 & 1,42 & 26,15 \\
$\mathbf{4}$ & A carne suína apresenta alta quantidade de colesterol & 5,05 & 1,57 & 31,09 \\
$\mathbf{5}$ & Carne suína tem melhor preço do que outras cartas & 4,88 & 1,63 & 33,40 \\
$\mathbf{6}$ & A exposição de carne suína é menor & 4,65 & 1,79 & 38,49 \\
$\mathbf{7}$ & A carne suína é uma carne fácil de ser preparada & 4,62 & 1,82 & 39,39 \\
$\mathbf{8}$ & O manejo da carne suína é feito de forma higiênica & 4,55 & 1,41 & 30,99 \\
$\mathbf{9}$ & A carne suína é uma carne saudável & 4,53 & 1,67 & 36,87 \\
$\mathbf{1 0}$ & Carne suína tem pouca variedade de corte & 4,26 & 1,83 & 42,96 \\
$\mathbf{1 1}$ & Menos promoções de carne suína do que outras carnes & 4,25 & 1,75 & 41,18 \\
$\mathbf{1 2}$ & A criação de suínos é feita de forma higiênica & 4,10 & 1,54 & 37,56 \\
$\mathbf{1 3}$ & O consumo de carne suína é um hábito & 4,02 & 1,86 & 46,27 \\
$\mathbf{1 4}$ & Carne suína é mais difícil de ser encontrada no mercado & 3,10 & 1,75 & 56,45 \\
\hline Fonte elaborado pelos autors
\end{tabular}

Fonte: elaborado pelos autores.

Observa-se, na Tabela 1, que os atributos de números 1 e 2 chamaram a atenção em virtude de se aproximaram da nota 6 , de que concordavam que a carne suína é macia e saborosa. Numa pesquisa realizada com consumidores gregos, verificou-se que esses estão satisfeitos com a carne suína nos atributos sabor, maciez e suculência (PAPANAGIOTOU et al., 2013). Segundo Saab (2005), no Brasil, o sabor também é considerado o atributo que traz mais satisfação em relação à carne suína.

Nos atributos de 5 a 9, na Tabela 1, as notas se aproximaram de 5, de que os consumidores concordavam parcialmente de que a carne suína apresenta altos teores de gordura e de colesterol, que o seu preço é menor do que os das carnes bovina e de frango, que é uma carne saudável, fácil de ser preparada e que o seu manejo é feito de forma higiênica. Segundo Cobra (2009), no Brasil o preço da carne suína, por ser mais barata do que a carne bovina, é o grande diferencial que favorece o seu consumo. Já, em relação ao teor de gordura e colesterol, eram as preocupações de 38,4\% dos consumidores de Belo Horizonte (MG), e que inibiam o consumo desse tipo de carne. Segundo Faria et al. (2006), esse fato caracteriza um desconhecimento das qualidades da carne suína, pois alguns cortes dessa carne têm o mesmo teor de gordura e colesterol, ou até menor, quando comparados a alguns cortes de carne bovina ou de frango.

No bloco de atributos de 10 a 13, as notas estão em torno de 4, sugerindo uma indiferença, de não concordar e nem discordar com tais atributos: de que há pouca variedade de cortes dessa carne à disposição do consumidor; que há menos promoções de carne suína do que as de frango e bovina nos locais de compra; de que a criação de suínos é higiênica e; de que o consumo dessa carne é um hábito. Schlindwein e Kassouf (2006) relatam que um fator limitante para uma maior demanda da carne suína se deve a falta de cortes específicos de baixo valor agregado para a população de baixa renda.

O último atributo, com média 3 (discorda parcialmente), era o de que a carne suína era mais difícil de ser encontrada quando comparada às carnes bovina e de frango. Isso mostra uma certa organização da cadeia produtiva da carne suína em Campo Grande, pois não existem grandes dificuldades em encontrar esse produto no comércio varejista. 
Ainda, com relação à Tabela 1 , os desvios padrão têm altos valores relativos às médias aritméticas, acima de $30 \%$, o que indica respostas heterogêneas, que não existe uma opinião geral formada a respeito dos assuntos tratados. Só existem homogeneidades relativamente boas nos dois primeiros atributos, sobre a maciez e o sabor da carne suína, respectivamente, com valores 15,36\% e 20,72\%.

\subsection{NÃO CONSUMIDOR DE CARNE SUÍNA IN NATURA EM CAMPO GRANDE}

Em relação aos não consumidores de carne suína in natura foram feitas dezesseis perguntas em escala de Likert de 7 pontos $(1=$ discordo totalmente até 7 = concordo totalmente), adotando os mesmos critérios que foram utilizados para os consumidores de carne suína. Os resultados estão mostrados na Tabela 2.

Tabela 2 - Parâmetros (média, desvio padrão (DP) e coeficiente de variação (CV)) sobre as propriedades da carne suína do ponto de vista dos não consumidores dessa carne, Campo Grande, em 2013.

\begin{tabular}{clccc}
\hline $\mathbf{N}$ & Atributo da carne suína (não consumidor) & Média & DP & $\mathbf{C V}(\%)$ \\
\hline $\mathbf{1}$ & Alta quantidade de gordura & 5,40 & 1,74 & 32,22 \\
$\mathbf{2}$ & Alta quantidade de colesterol & 5,31 & 1,83 & 34,46 \\
$\mathbf{3}$ & Apresenta risco a saúde & 5,15 & 1,76 & 34,17 \\
$\mathbf{4}$ & Pouca condição de higiene do suíno & 4,86 & 1,90 & 39,09 \\
$\mathbf{5}$ & Más condições de conservação & 4,52 & 1,98 & 43,81 \\
$\mathbf{6}$ & Sabor ruim & 4,40 & 2,26 & 51,36 \\
$\mathbf{7}$ & Falta de hábito & 4,26 & 2,02 & 47,42 \\
$\mathbf{8}$ & Baixa qualidade da carne suína & 4,26 & 2,00 & 46,95 \\
$\mathbf{9}$ & Má aparência da carne suína & 4,15 & 2,09 & 50,36 \\
$\mathbf{1 0}$ & Pouca variedade de cortes & 3,49 & 1,97 & 56,45 \\
$\mathbf{1 1}$ & Preconceito em relação à carne suína & 3,04 & 1,95 & 64,14 \\
$\mathbf{1 2}$ & Pouca divulgação no mercado consumidor & 3,04 & 1,95 & 64,14 \\
$\mathbf{1 3}$ & É uma carne dura & 2,98 & 1,56 & 52,35 \\
$\mathbf{1 4}$ & Alto preço alto da carne suína & 2,70 & 1,81 & 67,04 \\
$\mathbf{1 5}$ & Dificuldade de encontrar a carne suína & 2,28 & 1,50 & 65,79 \\
$\mathbf{1 6}$ & Religião não permite & 2,10 & 1,50 & 71,43 \\
\hline Fonte & elaborado pelos autores & & &
\end{tabular}

Fonte: elaborado pelos autores

As propriedades sobre a carne suína, dos pontos de vistas dos não consumidores, com atributos de 1 a 5 , têm médias em torno de 5, indicando que esses indivíduos concordavam parcialmente com o fato de a carne suína ter alta quantidade de gordura, alto teor de colesterol, de ser mal conservada, de oferecer risco à saúde e poucas condições de higiene do suíno. Sobre os altos teores de gordura e colesterol da carne suína, esses mitos também persistem entre os não consumidores. Os coeficientes de variação relativos a esses 5 atributos têm valores acima de $30 \%$ indicando uma grande heterogeneidade nas respostas.

As propriedades de 6 a 9 , da Tabela 2, apresentam médias aritméticas em torno de 4, isto é, os não consumidores de carne suína eram indiferentes às afirmações de que a carne suína tem sabor ruim, que tem baixa qualidade e, má aparência.

Com médias aritméticas em torno de 3 estão os atributos de 10 a 14 da Tabela 2, isto é, os consumidores discordam parcialmente de que a carne suína tenha pouca variedade de cortes, que existem preconceitos relativos a essa carne, que essa carne é dura, que tem preço alto e, que existe pouca divulgação a respeito da mesma em supermercados e açougues. Mas, segundo Schlindwein e Kassouf (2006), o menor consumo da carne suína em relação à carne bovina e de frango se 
deve aos mitos e lendas, de que a carne suína faz mal à saúde. Ainda, de acordo com os mesmos autores, o menor consumo de carne suína é devido, também, à falta de cortes de baixo valor agregado, acessíveis à população de baixa renda.

Os não consumidores de carne suína in natura discordam das afirmações colocadas sobre as dificuldades de se encontrar essa carne em supermercados e açougues da cidade, bem como, de que o não consumo era em virtude da religião, pois, os dois atributos têm médias 2,0. De um modo geral, os coeficientes de variação dos 16 atributos da carne suína da Tabela 2 estão muito altos, variando de 32 a $71 \%$, indicando que não existe uma opinião formada sobre os motivos que levaram esses indivíduos a não consumirem carne suína.

\subsection{COMPORTAMENTO DO CONSUMIDOR DE CARNE SUÍNA IN NATURA}

$\mathrm{Na}$ Tabela 3 estão resumidos os cruzamentos das variáveis envolvendo vários atributos sobre a carne suína, do ponto de vista dos consumidores dessa carne, com a variável "frequência de consumo da carne suína", segmentados pelos gêneros masculino (M) e feminino (F). Realizou-se, também, o teste do Quiquadrado de associação entre as duas variáveis cruzadas, com o cálculo da significância $p$. Considerou-se significativas as associações para $p \leq 0,05$, e pouco significativas para $0,05<p \leq 0,10$.

Tabela 3 - Cruzamentos entre duas variáveis V1 e V2 para os consumidores de carne suína in natura, segmentados pelos gêneros masculino $(M)$ e feminino (F), com o cálculo do nível de significância $p$.

\begin{tabular}{clccc}
\hline \multicolumn{2}{c}{ Cruzamento de variáveis (consumidor de carne suína) } & \multicolumn{2}{c}{ Significância } \\
\hline $\mathbf{N}$ & \multicolumn{1}{c}{ Variável V1 } & Variável V2 & $\mathbf{M}$ & $\mathbf{F}$ \\
\hline 1 & Propaganda sobre a carne suína & Freq. de consumo & $\mathrm{p}=0,44$ & $\mathrm{p}=0,02^{*}$ \\
2 & Veículo de comunicação & Freq. de consumo & $\mathrm{p}=0,26$ & $\mathrm{p}=0,04^{*}$ \\
3 & Variedade de cortes & Freq. de consumo & $\mathrm{p}=0,04^{*}$ & $\mathrm{p}=0,19$ \\
4 & Carne suína apresenta bom sabor & Freq. de consumo & $\mathrm{p}=0,45$ & $\mathrm{p}=0,06^{* *}$ \\
5 & Facilidade de preparo & Freq. de consumo & $\mathrm{p}=0,41$ & $\mathrm{p}=0,03^{*}$ \\
6 & Higiene na criação de suínos & Freq. de consumo & $\mathrm{p}=0,59$ & $\mathrm{p}=0,09^{* *}$ \\
7 & Manejo higiênico da carne & Freq. de consumo & $\mathrm{p}=0,09^{* *}$ & $\mathrm{p}=0,12$ \\
8 & Quantidade de colesterol & Freq. de consumo & $\mathrm{p}=0,07^{*}$ & $\mathrm{p}=0,03^{*}$ \\
9 & Quantidade de gordura & Freq. de consumo & $\mathrm{p}=0,19$ & $\mathrm{p}=0,06^{* *}$ \\
10 & Exposição da carne suína no varejo & Freq. de consumo & $\mathrm{p}=0,80$ & $\mathrm{p}=0,10$ \\
11 & Consumo de carne suína é hábito & Freq. de consumo & $\mathrm{p}=0,01^{*}$ & $\mathrm{p}=0,01^{*}$ \\
\hline
\end{tabular}

*Dependência significativa; **Dependência pouco significativa.

Fonte: elaborado pelos autores.

Algumas constatações podem ser tiradas da Tabela 3: no cruzamento das variáveis "Propaganda sobre a carne suína" e "Frequência de consumo", a associação não foi significativa para sexo masculino $(p=0,44)$ e significativa para o sexo feminino $(p=0,02)$. Conclui-se que pessoas do sexo feminino são mais susceptíveis à propaganda. A propaganda é uma ferramenta poderosa e, pode ser usada para persuadir o consumidor ao consumo de um produto. Com relação à variável "Veículo de comunicação x frequência de consumo", novamente, a associação entre as variáveis foi significativa para as mulheres $(p=0,04)$ e não 
significativa para os homens $(p=0,26)$. Segundo Kotler (1998), para que a propaganda traga bons resultados, ela deve ser direcionada de maneira específica, ou seja, escolher veículos de comunicação que atinjam o público alvo.

O gênero masculino está inclinado a aumentar a frequência de consumo de carne suína ao ter essa carne mais variedade de cortes $(p=0,04)$, mas as mulheres não sofrem influencia dessa variável $(p=0,19)$. Segundo Saab (2005), o consumo de carne suína no Brasil não é maior devido a pouca variedade de cortes, entre outros.

Em relação ao atributo sabor e frequência de consumo, a dependência não foi significativa para sexo masculino $(p=0,45)$, sendo pouca significativa para sexo feminino $(p=0,06)$, estando às mulheres mais propensas a consumirem com mais frequência carne suína, pois acham que a mesma apresenta um bom sabor. Segundo Faria et al. (2006), o sabor é o principal motivo para o consumo de carne suína in natura pelos consumidores de Belo Horizonte, MG.

A mulher poderia aumentar sua frequência de consumo de carne suína desde que a mesma apresentasse cortes com maiores facilidades de preparo $(p=0,03)$, já 0 sexo masculino não é influenciado por essa variável $(p=0,41)$. Segundo Schlindwein e Kassouf (2006), a urbanização e a inserção da mulher no trabalho fora de casa trouxe uma busca por alimentos com praticidade de preparo.

Os homens estão inclinados, de certa forma, a consumir com mais frequência à carne suína se, do seu ponto de vista, essa carne fosse processada de forma higiênica $(p=0,09)$. Essa variável não influencia o comportamento das mulheres $(p=0,12)$. Já a variável criação de suínos de maneira higiênica poderia influenciar o aumento da frequência de consumo de carne suína por parte das mulheres $(p=0,09)$, e não influencia os homens $(p=0,59)$. Com consumidores de quatro países (França, Dinamarca, Suécia e Reino Unido), mostrou que alguns consumidores estão preocupados com a forma do sistema produtivo dessa carne, ou seja, segurança, bem-estar animal e da poluição ambiental (DRANSFIELD et al., 2005).

A variável alta quantidade de colesterol afeta de maneira significativa a frequência de consumo das mulheres $(p=0,03)$ e de maneira pouco significativa os homens $(p=0,07)$, indicando que, quanto menos colesterol percebido, maior seria a frequência de consumo dessa carne para os dois gêneros. Essa preocupação vem de encontro com resultados de uma pesquisa com os consumidores gregos, os quais, apesar de serem influenciados pela satisfação com a carne suína devido os atributos como sabor, maciez e suculência, há um segmento que prefere carne suína magra, devido ao estilo de vida moderno, ou seja, preocupação com a saúde (PAPANAGIOTOU et al., 2013).

A alta quantidade de gordura da carne suína percebida por consumidores do sexo feminino, faz com que esse gênero reduza a frequência de consumo dessa carne $(p=0,06)$, não influenciando o gênero masculino $(p=0,19)$. Na cidade de Campinas, SP, verificou que os atributos gordura, colesterol e calorias influenciaram mais na intenção de consumir do que os atributos relacionados com a segurança alimentar da carne suína (FONSECA; SALAY, 2008).

Mesmo que a carne suína tenha mais exposição no comércio, a frequência de consumo dessa carne não será afetada pelo sexo masculino $(p=0,80)$. Já as mulheres estão mais inclinadas a serem influenciadas por uma maior exposição do produto $(p=0,10)$. Segundo Kotler (1998), a ferramenta promoção gera vendas mais rápidas e influencia o comportamento do consumidor. Suas atividades englobam: exposições e feiras, amostras, prêmios e vales brindes, cupons, concursos e jogos (LAS CASAS, 2009).

A variável hábito influencia a frequência de consumo da carne suína para ambos os sexos $(p=0,01)$. Para Blackwell et al. (2011) a cultura influencia o comportamento do consumidor, ou seja, o hábito de consumo de certo produto tem 
influência da cultura. Desse modo, há a necessidade de ações de marketing para tornar o consumo desse produto um hábito.

Realizou-se, também, cruzamentos de variáveis ligadas ao perfil do consumidor com a frequência de consumo, segmentados pelos gêneros masculino (M) e feminino (F) e o cálculo da significância $p$ da associação entre as variáveis pelo teste do Qui-quadrado, com a finalidade de se observar se o perfil do indivíduo tem alguma influência na frequência de consumo de carne suína. Os resultados estão na Tabela 4.

Tabela 4 - Cruzamento entre duas variáveis V1 e V2 ligadas ao perfil do consumidor de carne suína com variável frequência de consumo, com o cálculo da significância p.

\begin{tabular}{clcccc}
\hline & \multicolumn{2}{c}{ Cruzamento (consumidor de carne de carne suína) } & & \multicolumn{2}{c}{ Teste Qui-quadrado } \\
\cline { 1 - 2 } $\mathbf{N}$ & Variável V1 & Variável V2 & & Masc. & Fem. \\
\hline 1 & Faixa etária & Freq. de consumo & & $\mathrm{p}=0,60$ & $\mathrm{p}=0,00^{*}$ \\
2 & Escolaridade & Freq. de consumo & & $\mathrm{p}=0,08^{\star *}$ & $\mathrm{p}=0,00^{*}$ \\
3 & Renda & Freq. de consumo & & $\mathrm{p}=0,31$ & $\mathrm{p}=0,19$ \\
4 & Local de aquisição & Freq. de consumo & $\mathrm{p}=0,09^{\star *}$ & $\mathrm{p}=0,63$ \\
5 & Região que mora & Freq. de consumo & $\mathrm{p}=0,35$ & $\mathrm{p}=0,84$ \\
6 & Origem da carne & Freq. de consumo & $\mathrm{p}=0,41$ & $\mathrm{p}=0,28$ \\
\hline
\end{tabular}

Dependência significativa; "Dependência pouco significativa.

Fonte: elaborado pelos autores.

Sobre a Tabela 4, algumas evidências foram constatadas: a faixa etária não influencia a frequência de consumo da carne suína para os homens $(p=0,60)$, mas tem influência altamente significativa sobre as mulheres $(p=0)$. Segundo Papanagiotou et al. (2013), em uma pesquisa realizada com consumidores gregos, verificou-se que a idade parece influenciar o processo de percepção da qualidade da carne suína e também a intenção de compra desse produto, contrariando em parte 0 que foi constatado nesta pesquisa.

A frequência de consumo de carne suína é muito influenciada pelo nível de escolaridade das mulheres $(p=0)$, e pouco influenciada pelo nível de escolaridade dos homens $(p=0,08)$. A renda familiar não influencia a frequência do consumo de carne suína, tanto para o gênero masculino $(p=0,31)$ quanto para o gênero feminino $(p=0,19)$. Segundo Cobra (2009), no Brasil, o preço da carne suína, por ser mais barata do que a carne bovina, é o grande diferencial que favorece o seu consumo. $O$ local de aquisição da carne suína no mercado varejista tem pouca influência sobre os homens na frequência de consumo desse produto $(p=0,09)$, não influenciando as mulheres $(p=0,63)$. A origem da carne suína não teve nenhuma influência na frequência de consumo, $(p=041)$ para os homens e $(p=0,28)$ para as mulheres. Verificou em pesquisa com consumidores de quatro países europeus: França, Dinamarca, Suécia e Reino Unido, que ao colocar etiquetas em cortres da carne suína com informações sobre a origem dessa carne (local de criação), há uma preferencia da carne suína proviniente do seu próprio país, pagando até $5 \%$ a mais em detrimento da cane suína importada (DRANSFIELD at al., 2005).

\subsection{ANÁLISE FATORIAL}

Adotou-se o modelo de análise fatorial para o tratamento de grupos de variáveis de mesma natureza com o objetivo agrupar os consumidores em 
segmentos considerando as características demográficas e suas percepções a respeito da carne suína. $O$ objetivo da análise fatorial é identificar e reduzir o número de atributos sobre fatores relativos à compra de carne suína pelo consumidor, de forma que os fatores independentes extraídos explicassem, de forma simples, e reduzida, as variáveis originais agrupadas. O tamanho da amostra obedeceu ao critério recomendado por Malhotra (2001) e Hair et al. (2009), de cinco observações por variável.

\subsection{CONSUMIDOR DE CARNE SUÍNA IN NATURA}

Este bloco contém 14 questões correlacionadas entre si formando uma matriz quadrada simétrica de dimensão 14, em que na diagonal principal estão correlacionadas cada variável com si mesma, correlação 1 e, fora da diagonal principal, as correlações foram diferentes de zero, com nível de significância menor ou igual $5 \%$, o que equivale a $100 \%$ das combinações entre elas e que, segundo Hair et al. (2009), permite que se avance na verificação da adequação da análise fatorial.

A relação de variáveis desse bloco é a seguinte: "carne suína tem pouca variedade de corte, o consumo de carne suína é um hábito, carne suína apresenta um bom sabor, a carne suína é uma carne fácil de ser preparada, a carne suína é uma carne saudável, nos supermercados e/ou açougues há menos promoções de carne suína do que as de frango e bovina, a criação de suínos é feita de forma higiênica, o manejo da carne suína é feito de forma higiênica, a carne suína apresenta alta quantidade de colesterol, a carne suína apresenta melhor preço do que a carne de frango e bovina, a carne suína apresenta alta quantidade de gordura, carne suína é uma carne macia, nos supermercados e/ou açougues a carne suína é mais difícil de ser encontrada do que a de frango e bovina e, no comércio a exposição de carne suína é menor que outros tipos de carne".

Procedida a análise fatorial para os consumidores de carne suína, observando-se os critérios recomendados por Hair et al. (2009), e com a utilização do método varimax, chegou-se à Tabela 5 , com quatro fatores perfeitamente agrupados com as suas respectivas variáveis.

Tabela 5 - Matriz fatorial rotacionada das variáveis que influenciam na decisão de consumir carne suína. Campo Grande, MS, em 2013

\begin{tabular}{lcccc}
\hline \multicolumn{1}{c}{ Variável (consumidor de carne suína) } & \multicolumn{3}{c}{ Fator } \\
\cline { 2 - 5 } & \multicolumn{1}{c}{2} & 3 & 4 \\
\hline A carne suína é mais difícil de ser encontrada & 0,647 & & & \\
A exposição de carne suína é menor no comércio & 0,765 & & & \\
A criação de suínos é feita de forma higiênica & & 0,862 & & \\
O manejo da carne suína é feito de forma higiênica & & 0,871 & \multirow{2}{*}{0,783} & \\
A carne suína tem alta quantidade de colesterol & & & 0,780 & \\
A carne suína tem alta quantidade de gordura & & & & 0,761 \\
O consumo de carne suína é um hábito & & & & 0,667 \\
A carne suína apresenta um bom sabor & & & & 0,475 \\
A carne suína é uma carne saudável & & & &
\end{tabular}

Como pode ser observado na Tabela 5, cinco variáveis foram eliminadas, por não satisfazerem os critérios para a análise fatorial, são elas: "carne suína tem pouca variedade de corte, a carne suína é uma carne fácil de ser preparada, nos supermercados e/ou açougues há menos promoções de carne suína do que a de 
frango e bovina, a carne suína apresenta melhor preço do que a carne de frango e bovina e, carne suína é uma carne macia". Na Tabela 6 consta a nomeação de cada fator de acordo com as características das variáveis que compõe o mesmo.

Tabela 6 - Fatores nomeados de acordo com as características dos atributos dos consumidores de carne suína. Campo Grande, MS, em 2013

\begin{tabular}{lc}
\hline Fator & Nome do Fator \\
\hline Fator 1 & Disponibilidade do produto \\
Fator 2 & Processo produtivo \\
Fator 3 & Imagem do produto \\
Fator 4 & Qualidade do produto \\
\hline
\end{tabular}

Fonte: elaborado pelos autores.

Assim, no fator 1 ficaram agrupadas as variáveis "nos supermercados e/ou açougues a carne suína é mais difícil de ser encontrada do que a de frango e bovina" e, "menor exposição da carne suína no comércio do que outras carnes", podendo o fator ser representado pelo nome disponibilidade do produto. Pesquisa com consumidores brasileiros mostrou que o consumo de carne suína não é mais alto devido questões de disponibilização no ponto de venda dessa carne, entre outros (SAAB, 2005). O fator 2 está ligado ao processo produtivo, processo importante para qualquer organização, seja em relação à eficiência, qualidade ou diferenciador para o produto. Numa pesquisa realizada em quatro países (França, Inglaterra, Suécia e Dinamarca) verificou-se que o conhecimento do sistema produtivo da carne suína tem pouca relevância para esses e, não há ligação com o comportamento de compra (NGAPO et al., 2004).

Já, no fator 3 há um agrupamento das variáveis "carne suína tem alta quantidade de colesterol" e "gordura", podendo esse fator, diante dessas variáveis, ser nomeado como imagem do produto. A imagem que os consumidores têm sobre um produto influencia de certa forma seu consumo. Um estudo realizado em 2008 pela Coreia do Sul indicou que uma imagem negativa (publicidade negativa) em relação à segurança da carne bovina dos Estados Unidos da América, fez diminuir o consumo dessa carne pelos consumidores coreanos e, aumentar o consumo de carne suína (YOUN et al., 2012). O fator 4 apresentou três variáveis: "o consumo de carne suína é um hábito", "a carne suína apresenta um bom sabor" e, "a carne suína é uma carne saudável", podendo esse fator ser nomeado como qualidade do produto. A questão de qualidade é fundamental para qualquer produto, sendo um atributo relevante para o marketing (LAS CASAS, 2009).

\subsection{NÃO CONSUMIDOR DE CARNE SUÍNA IN NATURA}

Em relação aos indivíduos não consumidores de carne suína, também, foi feita a análise fatorial, utilizando-se os mesmos procedimentos e técnicas para os dados dos que consomem carne suína. As variáveis selecionadas neste bloco de não consumidores de carne suína foram as seguintes: "a religião não permite, por não ter hábito, pela pouca condição de higiene do suíno, pela alta quantidade de gordura, pela alta quantidade de colesterol, pelo preconceito em relação á carne suína, pela pouca variedade de cortes, pela baixa qualidade da carne suína, pela má aparência da carne suína, pelo sabor ruim, pelo preço alto da carne suína, pela dificuldade de encontrar a carne suína nos supermercado e açougues, por 
apresentar risco a saúde, pelas péssimas condições de conservação, pela pouca divulgação nos supermercados e/ou açougues e, por ser uma carne dura"

Com a utilização do método varimax chegou-se à Tabela 7 , com quatro fatores perfeitamente agrupados com as suas respectivas variáveis. Observa-se que quatro variáveis foram eliminadas por não satisfazerem as condições da análise fatorial. São elas: "por não ter hábito, pela pouca variedade de cortes, pela pouca divulgação nos supermercados e/ou açougues e por ser uma carne dura".

Tabela 7 - Matriz fatorial rotacionada das variáveis que influenciam na decisão de não consumir carne suína. Campo Grande, MS, em 2013.

\begin{tabular}{|c|c|c|c|c|}
\hline \multirow[t]{2}{*}{ Variável (consumidor de carne suína) } & \multicolumn{4}{|c|}{ Fator } \\
\hline & 1 & 2 & 3 & 4 \\
\hline Pela alta quantidade de gordura. & 0,94 & & & \\
\hline Pela alta quantidade de colesterol. & 0,96 & & & \\
\hline Pela pouca condição de higiene do suíno. & 0,58 & & & \\
\hline Pela baixa qualidade da carne suína. & & 0,76 & & \\
\hline Pela má aparência da carne suína. & & 0,63 & & \\
\hline Por apresentar risco a saúde. & & 0,59 & & \\
\hline Pelas péssimas condições de conservação. & & 0,73 & & \\
\hline Pelo sabor ruim. & & & 0,65 & \\
\hline Pelo preço alto da carne suína. & & & 0,86 & \\
\hline Dificuldade de encontrar a carne suína no varejo & & & 0,78 & \\
\hline Pois a religião não permite. & & & & 0,83 \\
\hline
\end{tabular}

$\mathrm{Na}$ Tabela 8 estão apresentados os fatores e seus respectivos nomes, seguindo os mesmos princípios de nomeação já adotados. Devido à dificuldade de se encontrar características em comum entre as variáveis do fator 3 , foi utilizado na sua nomeação o nome da variável com maior carga fatorial no fator, no caso, preço do produto, com carga fatorial 0,86, conforme sugerido por Hair et al. (2009).

Tabela 8 - Fatores nomeados de acordo com as características dos atributos dos não consumidores de carne suína. Campo Grande, MS, em 2013.

\begin{tabular}{lc}
\hline Fatores & Nomes \\
\hline Fator 1 & Imagem do produto \\
Fator 2 & Confiabilidade do produto \\
Fator 3 & Preço do produto \\
Fator 4 & Cultura \\
\hline elaborado pelos autores &
\end{tabular}

O fator 1 contém três variáveis e está relacionado à imagem do produto. Cobra (2009) afirma que a utilização das ferramentas de relações púbica é relevante junto aos consumidores, pois, permite construir a imagem das empresas ou dos seus produtos perante os consumidores e outros stakeholders. No fator 2 há quatro variáveis relacionadas à confiabilidade do produto. Numa pesquisa realizada com consumidores de carne (suína, bovina e de frango) em Campinas, SP, verificou-se que a questão da segurança (confiabilidade) influencia na intenção de consumir carne suína e bovina (FONSECA; SALAY, 2008).

No fator 3, nomeado de preço do produto, é muito relevante para a consolidação do produto no mercado varejista. Em uma pesquisa realizada por Resano et al. (2011), em quatro países europeus: Bélgica, Dinamarca, Alemanha, Grécia e Polónia, verificou-se que a variável preço se mostrou sensível para carne 
suína in natura e não para a processada. Finalmente, no fator 4 os dois atributos remanescentes: "a religião não permite" e "preconceito em relação á carne suína", está ligado à cultura dos indivíduos. Pesquisa com consumidores brasileiros demonstrou que o consumo da carne suína não é maior devido à questão cultural, entre outros (SAAB, 2005).

\section{CONCLUSÕES}

O mercado varejista de Campo Grande apresenta um bom potencial para o aumento do consumo da carne suína, pois, os consumidores acham que essa carne saborosa e macia, pontos fortes para esse produto que sofre concorrência direta com a carne bovina e de frango. A inibição a um maior consumo dessa carne se deve principalmente aos preconceitos que boa parte dos consumidores tem em relação à carne suína, de que é uma carne gordurosa e com alto teor de colesterol, portanto, o seu consumo é prejudicial à saúde. Em relação ao sistema de produção e comercialização da carne suína, os consumidores têm alguns preconceitos, principalmente sobre a higiene, tanto na criação do suíno quanto no manejo da carne, podendo influenciar de certa forma o seu consumo.

Os consumidores têm demonstrado uma preferência crescente por novos cortes, com agregação de valores, principalmente, no sentido de facilitar o seu preparo, com mais ênfase em relação ao gênero feminino, que atualmente tem ajudado na composição da renda da família e quer facilidade a hora do preparo das refeições. Como o preço da carne suína praticado no mercado varejista de Campo Grande não é um fator inibidor à frequência de consumo, o consumidor pode estar disposto a pagar mais na agregação de valores a novos cortes de carne suína.

O principal entrave no consumo da carne suína pode estar atrelado à falta de investimentos em marketing, pois, a maior parte das pessoas não tem conhecimento sobre a qualidade nutricional, os teores de gordura e colesterol quando comparados a outras carnes, a higiene na criação, manejo e comercialização da carne suína. Com isso, a frequência de consumo dessa carne pode ser aumentada, pois, como já foi dito, a maioria dos consumidores dessa carne é apreciador do seu sabor e maciez.

\section{REFERÊNCIAS}

ALCÂNTARA, R. L. C.; SOUZA, A. P. O. Alternativas de mercado para a agricultura: a realidade dos produtos hortícolas orgânicos no Brasil. In: BATALHA, M. O. (coord.). Gestão do agronegócio: textos selecionados. São Carlos: EdUFSCar, 2009. p. 263-306.

ABIPECS - Associação Brasileira de Indústria Produtora e Exportadora de Carne Suína - ABIPECS. Estatística do mercado interno, externo e mundial da carne suína. (2012). Disponível em: http://www.abipecs.org.br. Acesso em: 20 abr. 2013.

BLACKWELL, R. D.; MINIARD, P. W.; ENGEL, J, F. Comportamento do consumidor. São Paulo: Cengage Learning, 2011.

COBRA, M. Marketing básico: uma perspectiva. São Paulo: Atlas, 4. ed. 2009.

COELHO, K. C. Perfil do consumidor de hortaliças processadas no munícipio de Campo de Goytacozes. 2007. Dissertação do Mestrado em Produção Vegetal 
da Universidade Estadual do Norte Fluminense Darcy Ribeiro, Centro de Ciências e Tecnologia Agropecuárias - Rio de Janeiro.

DRANSFIELD, E. et al. Consumer choice and suggested price for pork as influenced by its appearance, taste and information concerning country of origin and organic pig production. Meat Science, v. 69, n. 1, p. 61-70, 2005.

ELIANE, K. Comportamento do consumidor: São Paulo: Atlas, 2. ed., 2008.

FARIA, I. G.; FERREIRA, J. M.; GARCIA, S. K. Mercado consumidor de carne suína e derivados em Belo Horizonte. Arquivo Brasileiro de Medicina Veterinária e Zootecnia, Belo Horizonte, v. 58, n. 2, 2006. p. 251-256.

FONSECA, J. S.; MARTINS, G. A. Curso de estatística. São Paulo: Atlas, 2006. p. 320.

FONSECA, M. C. P.; SALAY, E. Beef, chicken and pork consumption and consumer safety and nutritional concerns in the City of Campinas, Brazil. Food Controle, v. 19, 2008. p. 1051-1058.

GARVIN, D. A. Gerenciando a qualidade: a visão estratégica e competitiva. Rio de Janeiro: Qualitymark Ed. 1992. p. 357.

HAIR JUNIOR, J. F.; at al. Análise multivariada de dados. Porto Alegre: Bookman, 6. ed., 2009.

IBM-SPSS Software - Software e soluções de analítica preditiva da SPSS. Disponível em: http://www-01.ibm.com/software/br/analytics/spss/. Acesso em: 16 mai. 2016.

IBGE. Instituto Brasileiro de Geografia e Estatística. 2010. Censo Demográfico de 2010. Disponível em: http://www.ibge.gov.br. Acesso em: 24 jun. 2013.

KOTLER, P. Administração de marketing: análise, planejamento, implementação e o controle. São Paulo: Atlas, 5. ed., 1998.

LAS CASAS, A. L. Administração de marketing: conceitos, exercícios, casos. São Paulo: Atlas, 8. ed., 2009.

MALHOTRA, N. K. Pesquisa de marketing: uma orientação aplicada. Porto Alegre: Bookman. 4. ed., 2001.

MERA, C. M. P.; LORENZINI , R.; WOLLMANN. M. R. Percepção com suinocultores de Tapera/RS sobre o uso de dejetos suínos na lavoura e o impacto ambiental. Extensão Rural, Santa Maria, n. 21, p.77-100, Jan./Jun. 2011.

NGAPO, T. M. at al. Consumer perceptions: pork and pig production. Insights from France, England, Sweden and Denmark. Meat Science, v. 66, n. 1, 2004, p. 125134. 
PAPANAGIOTOU, P.; TZIMITRA-KALOGIANNI, I.; MELFOU, K. Consumers' expected quality and intention to purchase high quality pork meat. Meat Science, v. 93, n. 93, 2013, p. 449-454.

RESANO H. et al. Consumer satisfaction with pork meat and derived products in five European countries. Appetite, v. 56, 2011, p. 167-170.

ROPPA, L. Perspectivas da produção mundial de carnes, 2007 a 2015. Disponível em: http://www.sossuinos.com.br/mercado/info15.htm. Acesso em: 15 mai. 2013.

SAAB, M. S. B. L. M. Comportamento do consumidor de alimentos do Brasil: um estudo sobre a carne suína. 2005. Tese de Doutorado em Administração Faculdade de Economia, Administração e Contabilidade. Universidade de São Paulo (USP), São Paulo, 2005.

SCHLINDWEIN, M. M.; KASSOUF, A. L. Análise da influência de alguns fatores socioeconômicos e demográficos no consumo domiciliar de carnes no Brasil. Revista de Economia e Sociologia Rural, Rio de Janeiro, v. 44, n. 3, 2006, p. 549572.

SPEARS, R. Group Identities: The Social Identity Perspective. In: SCHWARTZ, S. J.; LUYCKX, K.; VIGNOLES, V. L. Handbook of identity theory and research. [S.I.]: Springer, v. 1: Structures and Processes, Cap. 9, p. 201-224, 2011.

SPHINX - Soluções em Coletas e Análises de Dados. Disponível em: http://www.sphinxbrasil.com/. Acesso em: 16 mai. 2015.

VENTURA, R. Mudanças no Perfil do Consumo no Brasil: Principais Tendências nos Próximos 20 Anos. MACROPLAN. Prospectiva, estratégia e gestão. Elaborado em agosto 2010. Disponível em: http://www.macroplan.com.br/Documentos/. Acesso em: 14 mai. 2015.

VITTI, V. at al. Comunicação no setor agroalimentar. In: CASTRO, L. T. (coord.). Marketing e estratégia em agronegócios e alimentos: textos selecionados. São Carlos: Atlas, 2011. p. 182-204.

YOUN, H.; LIM, B. I.; JIN, H. J. Differential effects of negative publicity on beef consumption according to household characteristics in South Korea. Health Policy. Seoul, v. 106, 2012, p. 138-148. 